\title{
Ectoparasite Habrobracon Hebetor Say Is an Efficient Biological Control Agent of Lepidopteran Pests
}

\author{
Irina Agasyeva* \\ Federal Research Centre of Biological Plant Protection, Krasnodar, 350039, Russian Federation
}

\begin{abstract}
Ectoparasite Habrobracon hebetor Say is one of the most widely used biological controllers in biological plant protection against a number of harmful lepidopterans, including especially dangerous pests of corn, soy, fruit and vegetable crops. As a result of research conducted in 2017, food specialization and parasitic activity of three different populations of H.hebetor were studied. Two races have been identified for mass rearing and application: pyralid and leaf roller (against corn moth, bean pod borer, apple and plum moths), and pyralid owl-moth (against cotton moth, corn borer, bean pod borer and boxwood moth). As a result of studies of biological features and trophic needs, it has been determined that caterpillars of mill moth (Ephestia cuhniellia Zella) should be used as a host insect for laboratory cultivation of the stock population of the Habrobracon pyralid and leaf roller race (race No. 1). For the introduced from South Kazakhstan the H.hebetor pyralid and noctuid race the most productive rearing is on the caterpillars of large bee moth (Galleria mellonela L.). Optimal temperature for rearing of both races is $26-28{ }^{\circ} \mathrm{C}$, relative air humidity is $70 \%$ and photoperiod is not less than 16 hours. It has been noticed that before laying eggs on the host's caterpillars, the Habrobracon female preliminarily paralyzes the victim, piercing the sheath with ovipositor. As a result, the caterpillar stops eating and is immobilized. In 3-4 days larvae hatch out of the laid on the caterpillar eggs. The larvae feed on the contents of the caterpillars for 4-5 days, then pupate and after 6-8 days an adult insect leaves the cocoon. The development of one generation lasts 13-16 days, one cocoon includes one parasite. 1,000 large bee moth caterpillars used for infection provide on average 5.8-6.0 thousand cocoons, of which an average of 4.5-4.7 thousand parasites fly out.
\end{abstract}

\section{Introduction}

Habrobracon hebetor Say is a highly effective parasite of caterpillars of many lepidopteran pests. Entomophage is one of the most used in biological plant protection - a bioagent for controlling the number of harmful species of noctuid (Noctuidae) and pyralid moths (Pyralidae). For many years it has been the object of mass cultivation and application

\footnotetext{
* Corresponding author: agasieva5@yandex.ru
} 
against a number of lepidopteran pests of agricultural crops [1,2]. The biological efficacy of a gabrobragon propagated under artificial conditions at low release rates (1-3 thousand individuals / ha) against a corn moth, cotton moth, and acacia moth reaches 70-90\%.

However, a number of researchers noted that the food chain of $H$. hebetor vary significantly, both in laboratory and in the field $[3,4]$. In this connection, it is artificially divided into pyralid, noctuid, leaf roller and other races. Obviously, as a result of microevolutionary processes, many biological parameters of this species have changed, such as food chain, stationary distribution, migration abilities, and morphogenetic structure of populations, which complicates its practical use in biological plant protection. In this regard, the study of the biological characteristics of $H$. hebetor will make it possible to determine the reasons for the variability of the structure of gabrobragon populations and the prospects for its further use in the natural regulation of the number of harmful Lepidoptera [5].

Researchers have found that each population of a bioagent has its own optimal development conditions - average daily temperature, relative humidity and photoperiod. For the Moldavian population, the optimal temperature is - $25^{\circ} \mathrm{C}$, the relative humidity is $60 \%$ and the photoperiod is 20 hours. For the Tajik and Uzbek populations, the optimal conditions for development are the temperature $-27^{\circ} \mathrm{C}$, the relative humidity - $60 \%$ and the photoperiod - 20 hours. Under such conditions their number increases by 9.1 and 15.2 times, respectively [6.7]. The Stavropol population of gabrobragon exhibits maximum activity at a temperature of $25-30{ }^{\circ} \mathrm{C}$ [8].

It should be noted that the gabrobracon, in contrast to the trichogramma, very quickly adapts to the conditions of breeding and use. At the same time, these two entomophages effectively complement each other and, by reducing the number of pests around cotton fields, postpone the infection of crops by 12-20 days [9, 10]. When released in the Stavropol Krai, the gabrobracon infected $64-87 \%$ of the noctuid caterpillars and $68-91 \%$ of the acacia pyralid caterpillars (Etiella zinckenella Tr.) [11].

The methods and timing of seasonal colonization of entomophages are essential for getting the maximum benefit from the use of parasites [12] ..

The aim of these studies was to assess the trophic specialization and biological efficacy of various geographical populations of gabrobragons maintained in the State Collection of Beneficial Organisms of the ARRIBPP against a number of lepidopteran species of the families Noctuidae, Pyralidae, Tortricidae.

\section{Materials and methods}

To assess trophic specialization in agrocenoses, caterpillars of the families Noctuidae, Pyralidae, Tortricidae were collected, which were offered the gabrobragon for infecting in the laboratory. The selected caterpillars of 35-40 individuals were placed in 0.7-liter jars and offered for infection to various races of gabrobragon. All experiments were carried out three times. The effectiveness of infection was determined by the number of paralyzed caterpillars and the emergence of parasites of the filial generation.

To assess the field effectiveness of the gabrobragon, in the laboratory we grew the gabrobragon pyralid and leaf roller race. The bioagent was grown on caterpillars of the mill moth (Ephestia kuehniella Zella). To maintain the stock culture of the mill moth, a mixture of wheat bran and flour whites is preliminarily sterilized for 1-2 days. before infection. Then the mixture is packaged in containers and the moth eggs are sieved onto the substrate at the rate of 0.5 eggs per $1 \mathrm{~kg}$ of the mixture. Caterpillars intended to infect $H$. hebetor were placed into 0.5 liter jars and gabrobrakan was introduced. The jars were tightened with a coarse calico napkin with a cotton swab moistened with a $20 \%$ sugar solution for feeding insects, and placed in a thermostat with a stable temperature $(+28-30){ }^{\circ} \mathrm{C}$. After 
11-13 days after infection the filial generation appeared. Optimum for breeding gabrobrakan is the temperature - $26-28{ }^{\circ} \mathrm{C}$, relative humidity - $70 \%$ and the photoperiod is not less than 16 hours.

\section{Results and discussion}

To study the trophic specialization of the gabrobragon population maintained in the laboratory, caterpillars from various Lepidoptera families were offered for infection (Table 1).

Table 1. Trophic specialization and parasitic activity of the pyralid and leaf roller race (population No. 1) Habrobracon hebetor Say

\begin{tabular}{|c|l|c|c|}
\hline \multirow{2}{*}{ Family } & Pest species & $\begin{array}{c}\text { Number of } \\
\text { paralyzed } \\
\text { caterpillars, \% }\end{array}$ & $\begin{array}{c}\text { Number of } \\
\text { parasitized } \\
\text { caterpillars, \% }\end{array}$ \\
\hline \multirow{3}{*}{ Tortricidae } & Green oak leaf roller (Tortix viridana L.) & 78,9 & 62,5 \\
\cline { 2 - 4 } & Apple moth (Cydia pomonella L.) & 66,7 & 47,4 \\
\cline { 2 - 4 } & Plum moth (Grapholitha funebrana Tr.) & 83,8 & 76,9 \\
\hline \multirow{2}{*}{ Pyralidae } & Corn borer (Ostrinia nubilalis Hb.) & 91,3 & 85,6 \\
\cline { 2 - 4 } & Bean pod borer (Etiella zinckenella Tr.) & 89,6 & 85,4 \\
\hline \multirow{2}{*}{ Noctuidae } & Cotton moth (Heliothis armigera Hbn.), & 38,0 & 0 \\
\cline { 2 - 4 } & Ragweed moth (Tarachidia candefacta Hub.) & 40,0 & 0 \\
\hline
\end{tabular}

It was found that the tested gabrobragon population introduced into laboratory culture in 2017 (population No. 1) effectively parasitizes on caterpillars of green oak leaf roller (Tortrix viridana L.), corn borer (Ostrinia nubilalis Hb.), bean pod borer (Etiella zinckenella Tr.) , plum moth (Grapholitha funebrana Tr.) and apple moth (Cydia pomonella L.). The share of caterpillars parasitized by gabrobragon when infecting a corn borer was $91.3 \%$, and the number of parasites that emerged was $85.6 \%$. When the bean pod borer was infested with gabrobragon, the number of caterpillars from which the parasites emerged was $85.4 \%$. Positive results were obtained when the caterpillars of the apple and plum moths were infected, the death of which was $67 \%$ and $84 \%$, respectively. The ragweed moth (Tarachidia candefacta Hubn.) was paralyzed by gabrobragon, but the parasite did not develop on it. The test population of the gabrobragon did not infect the cotton moth either. In this regard, the population of gabrobragon No. 1, maintained in the State collection of beneficial organisms of the ARRIBPP, was preliminarily isolated as a pyralid and leaf roller one (Figure 1).

In 2017, we carried out a detailed laboratory assessment of the food specialization and parasitic activity of the new $H$. hebetor population introduced from South Kazakhstan and maintained in the laboratory collection (Table 2).

Table 2. Trophic specialization and biological efficacy of the new Habrobracon hebetor Say race introduced from South Kazakhstan

\begin{tabular}{|c|c|c|c|c|c|}
\hline \multirow{2}{*}{ Pest species } & \multirow{2}{*}{$\begin{array}{c}\text { Number of } \\
\text { caterpillars, } \\
\text { ind. }\end{array}$} & \multicolumn{2}{|c|}{ Among them } & \multirow{2}{*}{$\begin{array}{l}\text { The number of } \\
\text { formed } \\
\text { parasite } \\
\text { cocoons, pcs. }\end{array}$} & \multirow{2}{*}{$\begin{array}{c}\text { The number } \\
\text { of emerged } \\
\text { adults of the } \\
\text { parasite, \% }\end{array}$} \\
\hline & & paralyzed, \% & parasitized, \% & & \\
\hline Corn borer & $78 \pm 3,0$ & 100 & 91 & $273 \pm 3,5$ & 94,3 \\
\hline Apple moth & $120 \pm 3,5$ & 100 & 0,0 & 0,0 & 0,0 \\
\hline Cotton moth & $69 \pm 2,5$ & 100 & 87 & $234 \pm 2,5$ & 88,4 \\
\hline Bean pod borer & $81 \pm 2,5$ & 100 & 55,6 & $195 \pm 3,0$ & 78,5 \\
\hline
\end{tabular}


As can be seen from the data presented in table 2, the new population (No. 2) has a high paralyzing activity against all tested species of lepidopteran pests, but parasitism was observed only on the cotton moth and moths (corn moth, acacia moth). In this connection, population No. 2 can be conditionally attributed to the noctuid and pyralid population.

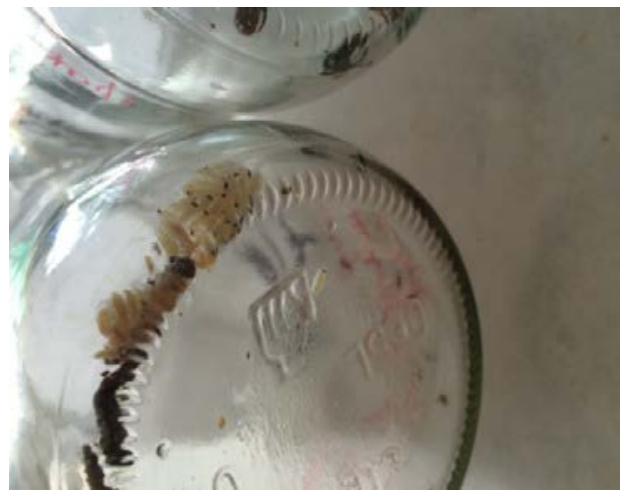

1

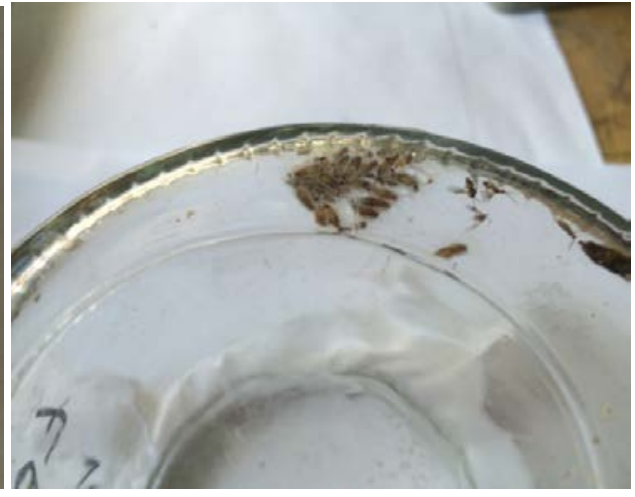

2

Fig. 1.- Laboratory assessment of trophic specialization and parasitic activity of $H$. hebetor Say: 1caterpillars of the Corn borer (O. nubilalis Hb.); 2 - caterpillars of the Bean pod borer (E. zinckenella Tr.)

It was additionally found that population No. 2 has a high parasitic activity against a particularly dangerous adventive pest - the boxwood moth (Cydalima perspectalis Walker) (Table 3).

Table 3. Parasitic activity of the noctuid race of the ectoparasite Habrobracon sp. against the boxwood moth (C. perspectalis Wal.).

\begin{tabular}{|l|c|c|c|c|}
\hline $\begin{array}{c}\text { Boxwood moth, } \\
\text { caterpillars }\end{array}$ & $\begin{array}{c}\text { Number of } \\
\text { caterpillars, } \\
\text { ind. }\end{array}$ & $\begin{array}{c}\text { \% infected by } \\
\text { the parasite }\end{array}$ & $\begin{array}{c}\text { Number of formed } \\
\text { cocoons, pcs. }\end{array}$ & $\begin{array}{c}\text { Number of the } \\
\text { emerged parasites, } \\
\text { \% }\end{array}$ \\
\hline Old age & $52 \pm 2,5$ & 100 & $41 \pm 2,5$ & 77,8 \\
\hline Middle age & $72 \pm 3,0$ & 100 & $12 \pm 3,0$ & 16,7 \\
\hline Young age & $58 \pm 2,0$ & 100 & 0,0 & 0,0 \\
\hline
\end{tabular}

In 2017, this gabrobragon race, in integration with entomopathogenic preparations and mass trapping of males with pheromone traps, was introduced into boxwood plantings on the territory of ARRIBPP, which together led to the complete suppression of the boxwood moth.

The results of the laboratory assessment of a new natural population captured during the 2018 faunal collection are of the great interest. The new laboratory population No. 3, caught on cassettes with a mill moth and previously assigned to the pyralid race, showed very ambiguous results in its laboratory assessment (Table 4). 
Table 4. Assessment of parasitic activity of the natural population of Habrobracon hebetor Say (population No. 3) caught in the Central zone of Krasnodar Krai, 2018

\begin{tabular}{|l|c|c|c|c|c|}
\hline \multirow{2}{*}{ Pest species } & \multirow{2}{*}{$\begin{array}{c}\text { Number of } \\
\text { caterpillars, } \\
\text { ind. }\end{array}$} & \multicolumn{2}{|c|}{ Among them } & \multirow{2}{*}{$\begin{array}{c}\text { The number of } \\
\text { formed parasite } \\
\text { cocoons, pcs. }\end{array}$} & $\begin{array}{c}\text { The number } \\
\text { of emerged } \\
\text { adults of the } \\
\text { parasite, \% }\end{array}$ \\
\hline Corn borer & $44 \pm 2,0$ & 50 & 0,0 & 0,0 & 0,0 \\
\hline Apple moth & $48 \pm 1,5$ & 25 & 0,0 & 0,0 & 0,0 \\
\hline Cotton moth & $38 \pm 2,0$ & 100 & 28 & 0,0 & 0,0 \\
\hline Plum moth & $32 \pm 2,5$ & 50 & 0,0 & 0,0 & 0,0 \\
\hline $\begin{array}{l}\text { Ear miner } \\
\text { moth }\end{array}$ & $22 \pm 1,0$ & 0 & 0,0 & 0,0 & 0,0 \\
\hline $\begin{array}{l}\text { Boxwood } \\
\text { moth }\end{array}$ & $34 \pm 2,0$ & 100 & 0,0 & 0,0 & 0,0 \\
\hline
\end{tabular}

The data presented in table 4 clearly show that population No. 3 has a high paralyzing activity against a number of pests (cotton moth, boxwood moth, corn borer). However, parasitism and release of the filial generation on the listed species of Lepidoptera were not observed. Based on this, it is difficult to talk about the trophic specialization of the new gabrobragon race. Further research is needed both in the laboratory and in the field.

The biological protection of plants against harmful insects is based primarily on the use of pests natural enemies - predators and parasites as bioagents to control them. Before using a bioagent in biological plant protection, it is necessary to study its biological characteristics.

As a result of studying the food specialization of the gabrobragon and other ecobiological features, caterpillars of the mill moth (Ephestia cuhniellia Zella) were chosen as a host insect for the laboratory cultivation of the stock population of the leaf roller ectoparasite race. The noctuid race of $H$. hebetor introduced from South Kazakhstan is maintained in the laboratory collection on the caterpillars of the large bee moth (Galleria mellonela L.). Optimum for breeding gabrobrakan are temperatures - $26-28{ }^{\circ} \mathrm{C}$, relative humidity - 70\% and photoperiod of at least 16 hours.

Thus, our studies of assessing the trophic specialization and parasitic activity of three populations of the $H$. Hebetor ectoparasite made it possible to identify new effective races specialized against a number of economically significant pests. It has been found that each population within a species has its own biological characteristics and food preferences. Often, intraspecific differences are reduced to differences in aggressiveness, which is especially important to take into account in biological plant protection.

The research was carried out with the financial support of the Kuban Science Foundation within the framework of the scientific project No. MFI-20.1 / 65

\section{References}

1. Agasyeva I. S., Ismailov V. Ya., Fedorenko E. V. et al. Development of methods for biological control of the codling moth for organic fruit growing technologies, Fruit and berry growing in Russia. 2019;56:97-106. DOI: 10.31676/2073-4948-2019-56-96-105

2. Dulgerova, V.A. Development of technology for breeding gabrobragon, Environmentally friendly and pesticide-free technologies for obtaining crop products: collection of the materials of the All-Russian scientific and production meeting. Krasnodar, 1994 Part 1, Pushchino, 1994, P. 140. 
3. Piekarska-Boniecka, Hanna, Marta Rzanska-Wieczorek, Idzi Siatkowski, et al. Controlling the Abundance of the Rose Tortrix Moth [Archips Rosana (L.)] by Parasitoids in Apple Orchards in Wielkopolska, Poland. Plant Protection Science. 2019;55:265-272. DOI: 10.17221/9/2019-pps.

4. Amarasekarea K.G., Shearer P.W., Mills N.J. Testing the selectivity of pesticide effects on natural enemies in laboratory bioassays. Biological Control, 2016, 102(C): 7-16 (doi: 10.1016/j.biocontrol.2015.10.015).

5. Chouinard G., Morin Y., Cormier. D. Seasonal Biology and Behaviour of the Predatory Mirid Hyaliodes Vitripennis, a Beneficial Insect of Apple Orchards in Quebec, Canada, Acta Horticulturae. 2019;1261:235-242. DOI: 10.17660/actahortic.2019.1261.34.

6. Standards for biological effectiveness of bioagents, standards and methods for determining their quality. - LLP "KazNII Plant Protection and Quarantine". - 2012 - 36 p.

7. Toleubaev K.M. Biological method in Kazakhstan: revival is real!, Journal "Plant Protection and Quarantine", 2014.

8. V.G. Kovalenkov, V. Ya. Ismailov, N.M. Tyurina [et al.], Ecological protection against pests of tomato, bell pepper and corn (under the conditions of the North Caucasus region), Production of ecologically safe crop products, Pushchino, 1995, P. 186-195.

9. Jumaev R.A., Kimsanboev X.X., Adilov M.M., Rustamov A.A., The technology of rearing Braconidae in Vitro in biolaboratory, Journal «European science review», 2017.

10. G. Kovalenkov, N.M. Tyurin, Breeding technology and application of gabrobragon ectoparasite, Methodical instructions, RAAS VNIIBZR Moscow, 1995, 48 p.

11. V.V. Kostyukov, O.V. Kosheleva, I. V. Balakhnina, Keys to the parasites of pests of the orchard, Rostov-on-Don, 2007, 229 p.

12. Frolov, A.N. Biotic factors of depression of the corn moth, Bulletin of plant protection, 2014, No. 2, P. 37-47. 